\title{
Progress in EUV resists towards high-NA EUV lithography
}

\author{
Xiaolong Wang ${ }^{\mathrm{a}^{*}}$, Zuhal Tasdemir ${ }^{\mathrm{a}}$, Iacopo Mochi ${ }^{\mathrm{a}}$, Michaela Vockenhuber ${ }^{\mathrm{a}}$, Lidia van Lent-Protasova ${ }^{\mathrm{b}}$, \\ Marieke Meeuwissen $^{\mathrm{b}}$, Rolf Custers ${ }^{\mathrm{b}}$, Gijsbert Rispens $^{\mathrm{b}}$, Rik Hoefnagels ${ }^{\mathrm{b}}$, Yasin Ekinci ${ }^{\mathrm{a}}$ \\ aPaul Scherrer Institute, CH-5232 Villigen PSI, Switzerland \\ ${ }^{\text {b} A S M L ~ N e t h e r l a n d s ~ B . V ., ~ D e ~ R u n ~ 6501, ~} 5504$ DR Veldhoven, The Netherlands
}

\begin{abstract}
High-NA extreme ultraviolet lithography (EUVL) is going to deliver the high-volume manufacturing (HVM) patterning for sub-7 nm nodes for the semiconductor industry. One of the critical challenges is to develop suitable EUV resists at high resolution with high sensitivity and low line-edge roughness (LER). The resist performance is generally limited by the resolution-LER-sensitivity (RLS) tradeoff and it is critical to find new resists that have a performance beyond this tradeoff. EUV interference lithography (EUV-IL) is a powerful and efficient technique that can print high resolution: half pitch (HP) down to $6 \mathrm{~nm}$ nanostructures. In this work, we evaluate the performance of the EUV resists, including molecular resist, inorganic resist, chemically-amplified (CAR) and metal sensitizer chemically-amplified resist (Metal-CAR). Six resists with the best performance have been compared in dose-to-size, line-edge roughness, exposure latitude for half pitch $16 \mathrm{~nm}$ and $14 \mathrm{~nm}$. The molecular resist A showed lowest dose to resolve HP $16 \mathrm{~nm}\left(35 \mathrm{~mJ} / \mathrm{cm}^{2}\right)$ and $14 \mathrm{~nm}\left(41 \mathrm{~mJ} / \mathrm{cm}^{2}\right)$ but with high line edge roughness (LER $3.5 \mathrm{~nm}$ ). CAR resist C provided lowest LER 1.9 and $1.8 \mathrm{~nm}$ for HP $16 \mathrm{~nm}$ and HP $14 \mathrm{~nm}$, respectively, but with higher doses $74 \mathrm{~mJ} / \mathrm{cm}^{2}$ (HP $16 \mathrm{~nm}$ ) and $69 \mathrm{~mJ} / \mathrm{cm}^{2}$ (HP $14 \mathrm{~nm}$ ). The inorganic resist showed comprehensive good performance, giving low LER of $2.1 \mathrm{~nm}$ with $50 \mathrm{~mJ} / \mathrm{cm}^{2}$ and $42 \mathrm{~mJ} / \mathrm{cm}^{2}$ for $\mathrm{HP} 16 \mathrm{~nm}$ and HP $14 \mathrm{~nm}$, respectively. Using the simplified Z-factor model, we showed that the LER of the resists was improved over the last two years. As the inorganic resist could resolve HP $11 \mathrm{~nm}$ with dose $67 \mathrm{~mJ} / \mathrm{cm}^{2}$, we conclude it to be the current best candidate to partially resolve the RLS tradeoff problem and could be the potential EUV resist for semiconductor technological node printing.
\end{abstract}

Keywords: Extreme Ultraviolet lithography, EUVL, interference lithography, RLS, LER, High-NA, Resist CAR

\section{INTRODUCTION}

EUV lithography (EUVL) is predicted to deliver $7 \mathrm{~nm}$ node since 2015 [1, 2] and to deliver high volume manufacturing (HVM) in 2019 according to ASML EUVL roadmap [3]. In order to make sure that high-NA EUVL can be introduced to HVM on time, finding the best EUV resist that could outperform the resolution-LER-sensitivity (RLS) tradeoff [4] has been always a challenge in EUVL materials development. However, it is absolutely essential to develop, evaluate and understand the underlying mechanism of EUV resists. Also, a good EUV resist is one of the critical issues that decides whether EUV scanner could deliver the future nodes.

EUV interference lithography (EUV-IL) has been used to evaluate resist performance [2, 5-11]. One good advantage of EUV-IL is that we use the coherent light from synchrotron with the wavelength $\lambda=13.5 \mathrm{~nm}$, so the theoretical resolution limit of this technique is $3.5 \mathrm{~nm}$ [12], that is much higher than the EUV scanner with 0.33NA and the future high NA (0.55NA) [3]. The XIL-IL has successfully achieved world record of $6 \mathrm{~nm}$ HP [13] and demonstrated single digital

Extreme Ultraviolet (EUV) Lithography X, edited by Kenneth A. Goldberg, Proc. of SPIE Vol. 10957, 109570A · C 2019 SPIE · CCC code: 0277-786X/19/\$18 · doi: 10.1117/12.2516260 
resolution down to $2.5 \mathrm{~nm}$ technological node [12]. With the XIL-IL we can investigate the LER and sensitivity of the EUV resist platforms.

In this work, we present an overview of the state-of-art EUV resists from seven vendors over the year of 2017-2018. After evaluation of $\sim 150$ resists with different processing parameters, such as post-expose bake (PEB), post-apply bake (PAB), development time/materials, and resist thickness, we demonstrate six best performance resists for HP $16 \mathrm{~nm}$ and HP 14 $\mathrm{nm}$. We assessed the readiness of EUV resists for HVM high-NA EUVL by comparing critical parameters, including critical dimension (CD), dose, exposure latitude (EL) and LER, of the six resists categorized as four platforms (molecular resist, inorganic resist, CAR resist and Metal-CAR resist). We show that the inorganic resist gives a comprehensive good performance as it resolves HP $14 \mathrm{~nm}$ with a relatively low dose and very low LER. The inorganic resist also resolved HP down to $10 \mathrm{~nm}$ while CAR resist can reach HP down to $12 \mathrm{~nm}$. These resists are promising candidates for the HVM highNA EUVL resist based on its overall performance.

\section{EXPERIMENTAL METHODS}

The resist screening tests were performed with the EUV-IL tool at the at the XIL-II beamline of the Swiss Light Source (SLS). Figure 1 schematically shows the working principle of the XIL-IL tool we used in this work for two-beam interference. The transmission mask is illuminated perpendicularly with the plane wave (EUV light from the synchrotron SLS) polarized along the horizontal direction and the gratings. The diffracted beams from the grating interfere (with angle $\theta / 2$ ) on the surface of the photoresist-coated silicon wafer. We use the first-order diffracted beams for interference, and the relationship between the diffraction angle and the grating pitch is calculated as:

$$
\sin (\theta / 2)=\lambda / P
$$

where $\theta / 2$ is the diffraction angle and $P$ is the period of the grating. The period of the interfered sinusoidal aerial image is half of the grating period, which shows the advantage of the interference lithography. With the wavelength $\lambda=13.5 \mathrm{~nm}$, the theoretical resolution limit of the EUV-IL is $3.5 \mathrm{~nm}$ [12].

The gap between the mask and the wafer surface varies depending on the pitch of the grating and is determined with the following equation:

$$
g=\frac{d}{2 \tan (\theta / 2)}
$$

where $g$ is the gap between the grating and the interference pattern (mask-wafer distance) and $d$ is the distance between the two gratings. The formation of the aerial image can be line/space pattern, contact holes (CHs) or pillars pattern or pattern with triangle lattice [12]. Figures 1(b) and (c) show two different grating configurations, two-beam and four-beam, which produce line/space and CHs or pillars [14].

The aerial image obtained with IL is a sinusoidal pattern with $100 \%$ contrast, which is independent of the half-pitch. The aerial image has also infinite depth-of-focus, i.e. it is independent of the mask-to-wafer distance. Equation 2 defines the maximum overlap of the diffracted beams and divergence from the optimal gap leads to reduced patterning area.

After the exposures, the exposed line/space (L/S) patterns of photoresists were analyzed with SEM (Carl Zeiss SUPRA $55 \mathrm{VP}$ ) and critical dimension (CD), LER, and exposure latitude were obtained. The acceleration voltage $1 \mathrm{kV}$ and $7.5 \mu \mathrm{m}$ aperture were used for all resists. The CD and LER values were calculated with a commercial software SUMMIT (SuMMIT ${ }^{\circledR}$ ) and the LER values are estimated using $3 \sigma$ after a certain frequency filtering [15]. 


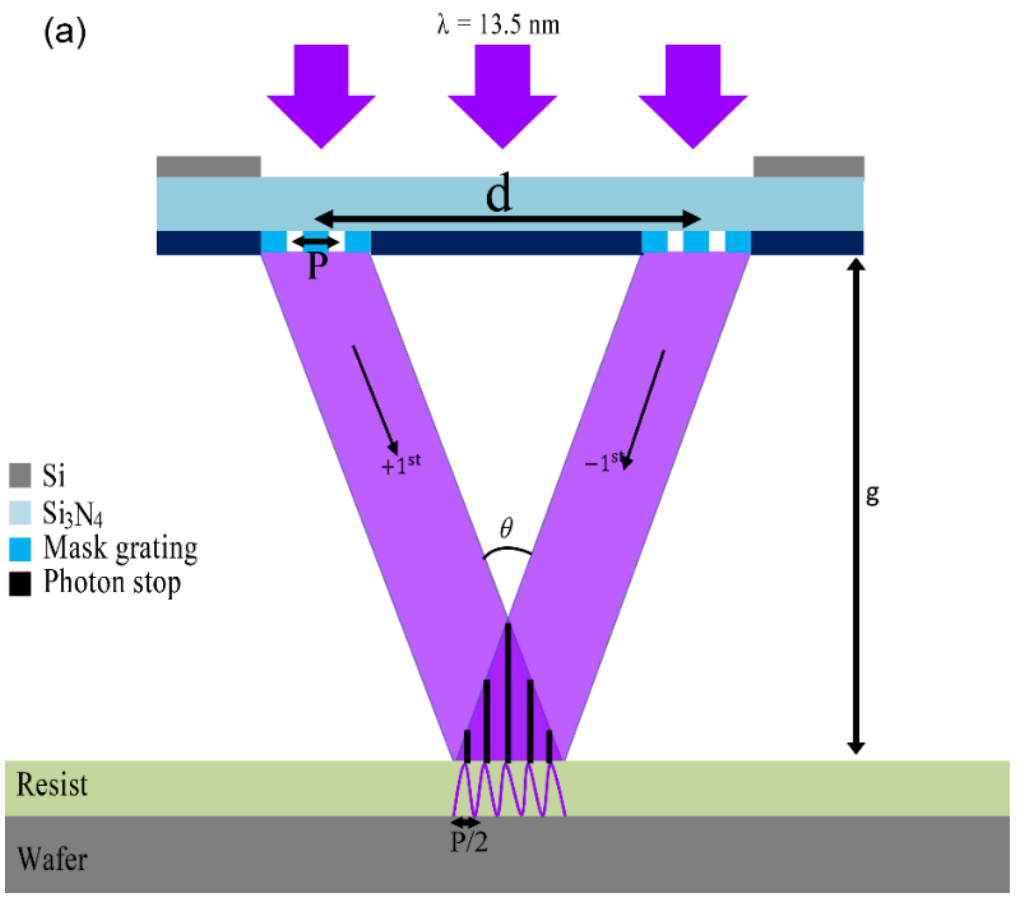

(b)

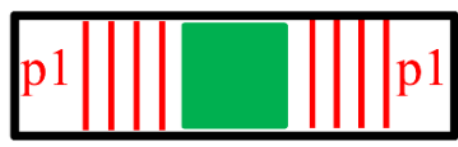

(c)

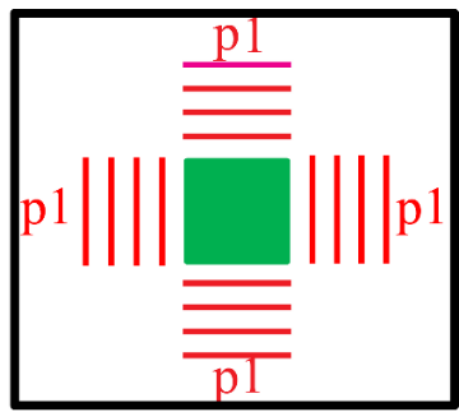

Figure 1. (a) EUV interference lithography scheme. For simplicity only two gratings and only the first-order diffraction beams are shown. A coherent EUV light illuminates a transmission mask, which consists of diffraction gratings. The diffracted beams form an interference pattern which is recorded in the photoresist. (b) Two-beam interference grating layout. (c) Grating arrangement for the case of coherent four-beam interference, yielding contact holes.

\section{RESULTS}

In this section, we present the performance of the resists, including molecular resist, inorganic resist, and CAR resist, which were delivered by seven vendors over the year of 2017-2018. We first show the six resists with the best performance out of $\sim 150$ resists for HP $16 \mathrm{~nm}$ and $14 \mathrm{~nm}$. Also, we give a statistical distribution of the selected good performance resists. The highest achievable resolution for different resists is displayed at the end, with the highest resolution down to HP $10 \mathrm{~nm}$ for inorganic resist.

The SEM images of the resists with the best performance for HP $16 \mathrm{~nm}$ are shown in Fig. 2. All the resists show good patterning at HP $16 \mathrm{~nm}$. The dose dependences of CD and LER for these resists are plotted in Fig. 3. We see the negativetone behavior for the resists A (molecular resist), B (inorganic resist), and C (negative-tone CAR).

Molecular resist A resolved HP $16 \mathrm{~nm}$ at the lowest dose-to-size (best energy (BE)): $35 \mathrm{~mJ} / \mathrm{cm}^{2}$ with LER $3.5 \mathrm{~nm}$. While the lowest LER and the highest exposure latitude were obtained for CAR resist C, the dose was high $\left(74 \mathrm{~mJ} / \mathrm{cm}^{2}\right)$; the zfactor was relatively low. The full comparison including exposure latitude for all the six resists is listed in Table 1. 
(a)

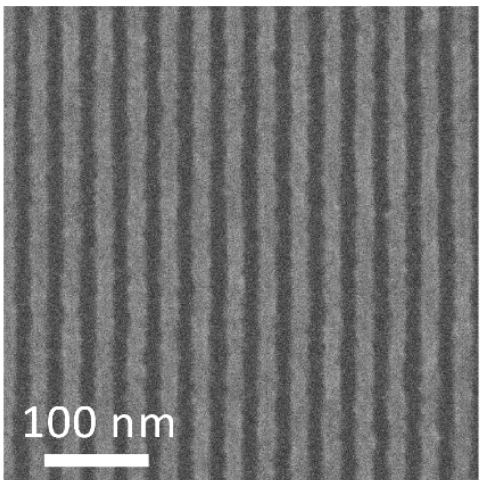

(d)

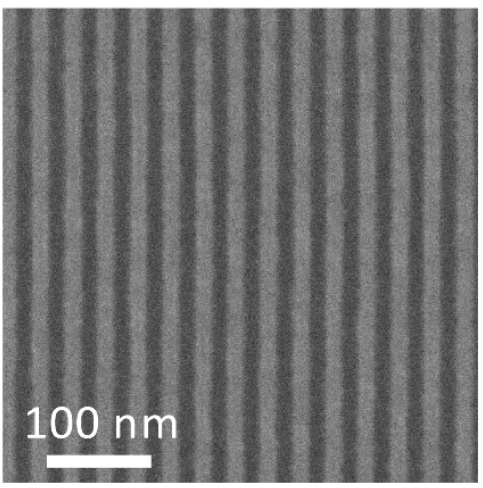

(b)

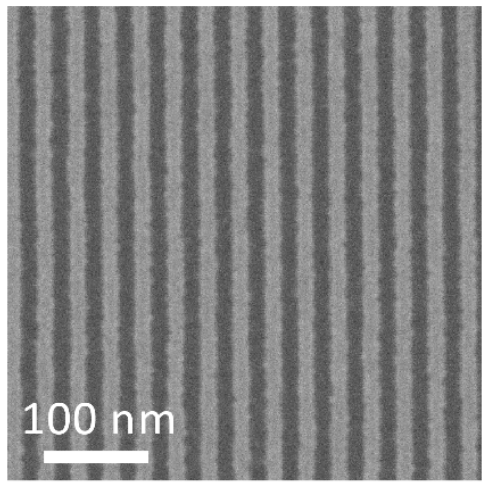

(e)

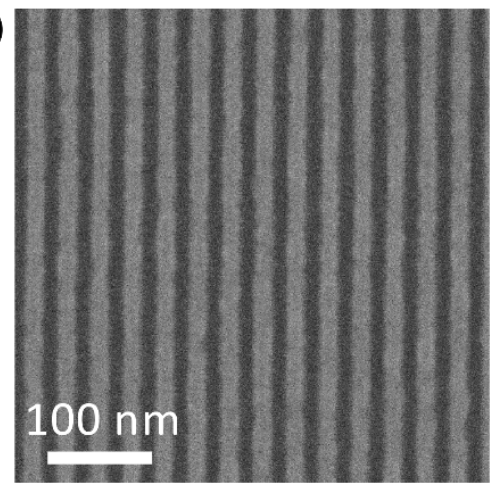

(c)

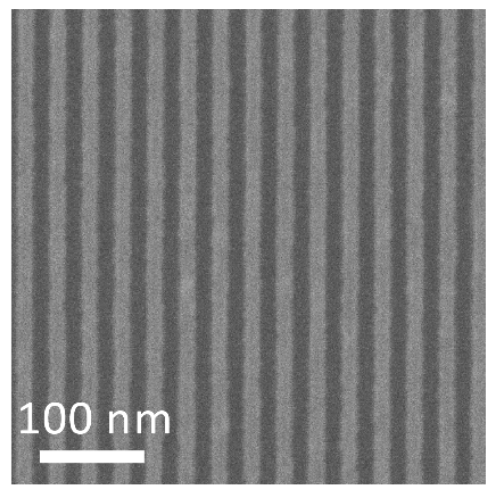

(f)

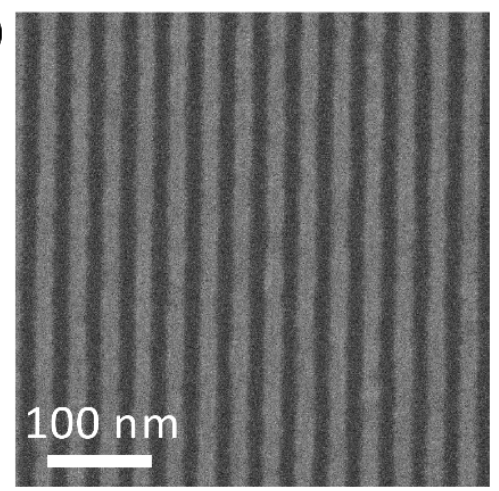

Figure 2. SEM images of selected resists at HP 16. (a) Molecular resist A. (b) Inorganic resist B. (c), (d), (e) and (f) CAR resists labeled as $\mathrm{C}, \mathrm{D}$, E, and F.
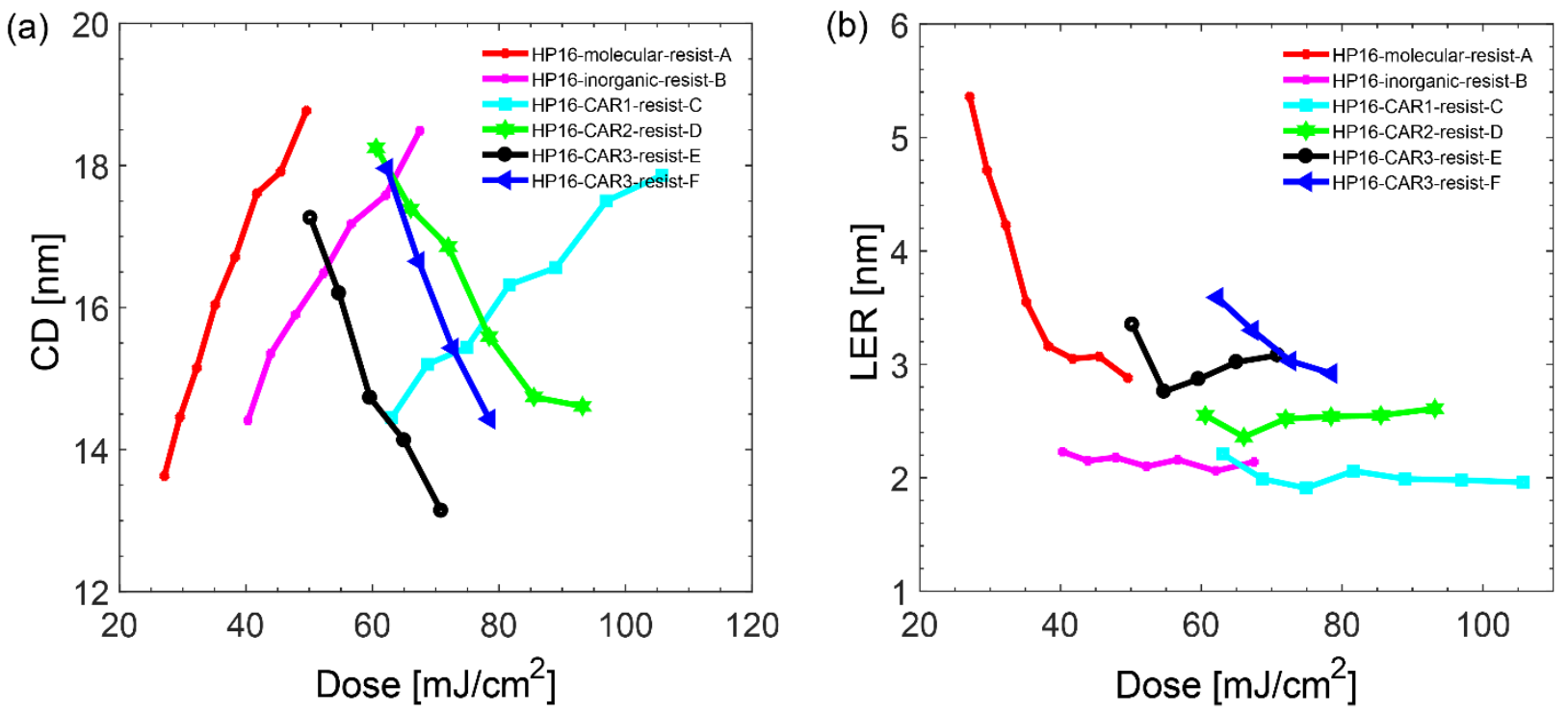

Figure 3. (a) CD to dose of the six best performance resists. (b) LER to dose of the six best performance resists. 
The inorganic resist B could be the best candidate for industrial technological node printing as it gives very low LER (2.1 $\mathrm{nm}$ ), and very high exposure latitude (36 \%) with relative high dose $50 \mathrm{~mJ} / \mathrm{cm}^{2}$, and the lowest z-factor.

The SEM images of the best performing resists are shown in Fig. 4. All resists resolved HP $14 \mathrm{~nm}$. The dose dependences of CD and LER for these resists are plotted in Fig. 5.

Table 1. CD, Dose-to-size (BE), EL and LER of the six best performance resists for HP $16 \mathrm{~nm}$.

\begin{tabular}{|c|c|c|c|c|c|}
\hline Vendor & Resist & Dose $\left(\mathrm{mJ} / \mathrm{cm}^{2}\right)$ & EL (\%) & LER (nm) & 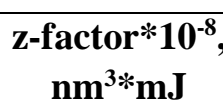 \\
\hline Vendor 1 & Molecular A & 35 & 27 & 3.5 & 1.8 \\
\hline Vendor 2 & Inorganic B & 50 & 36 & 2.1 & 0.9 \\
\hline Vendor 3 & CAR C & 74 & 41 & 1.9 & 1.1 \\
\hline Vendor 4 & CAR D & 78 & 25 & 2.5 & 2.0 \\
\hline Vendor 5 & CAR E & 54 & 13 & 2.7 & 1.6 \\
\hline Vendor 6 & CAR F & 72 & 8 & 3.0 & 2.7 \\
\hline
\end{tabular}

z-factor $=$ res $^{3 *}$ LER $^{2 *}$ dose

(a)

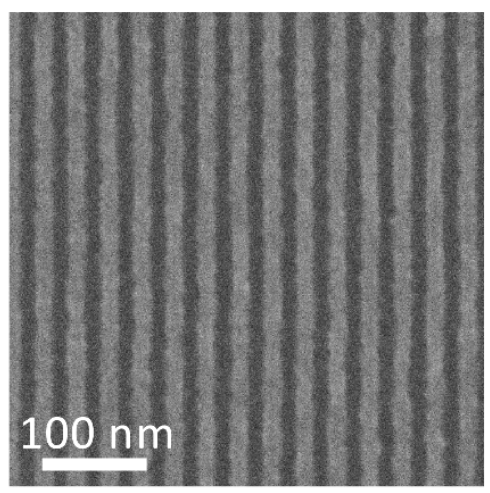

(d)

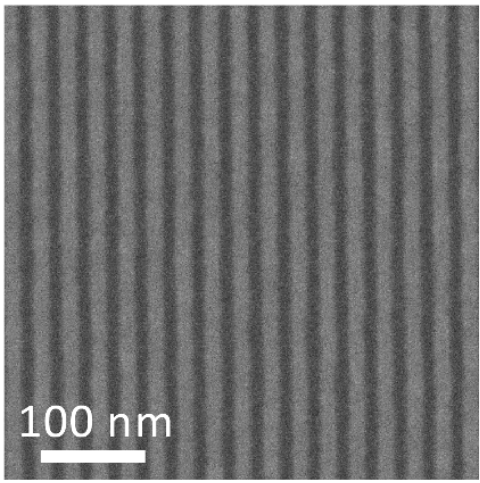

(b)

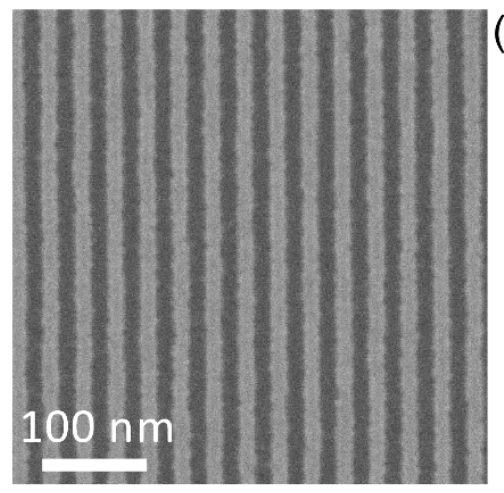

(e)

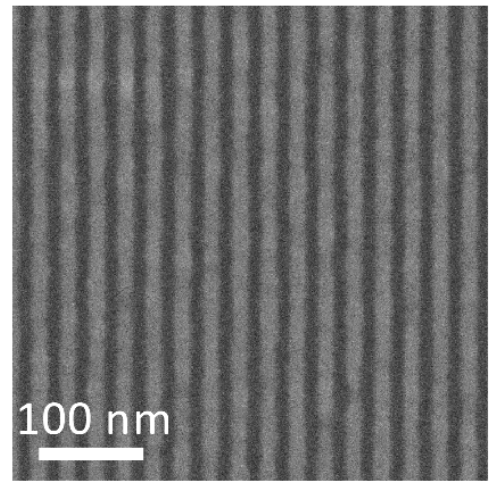

(c)

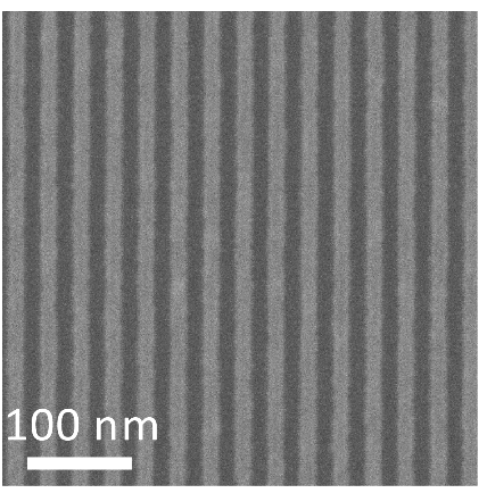

(f)

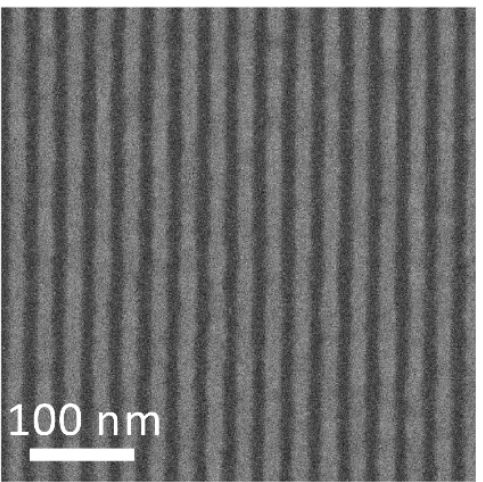

Figure 4. SEM images of selected resists for HP $14 \mathrm{~nm}$. (a) Molecular resist A. (b) Inorganic resist B. (c), (d), (e) and (f) CAR resists $\mathrm{C}, \mathrm{D}, \mathrm{E}$, and $\mathrm{F}$. 

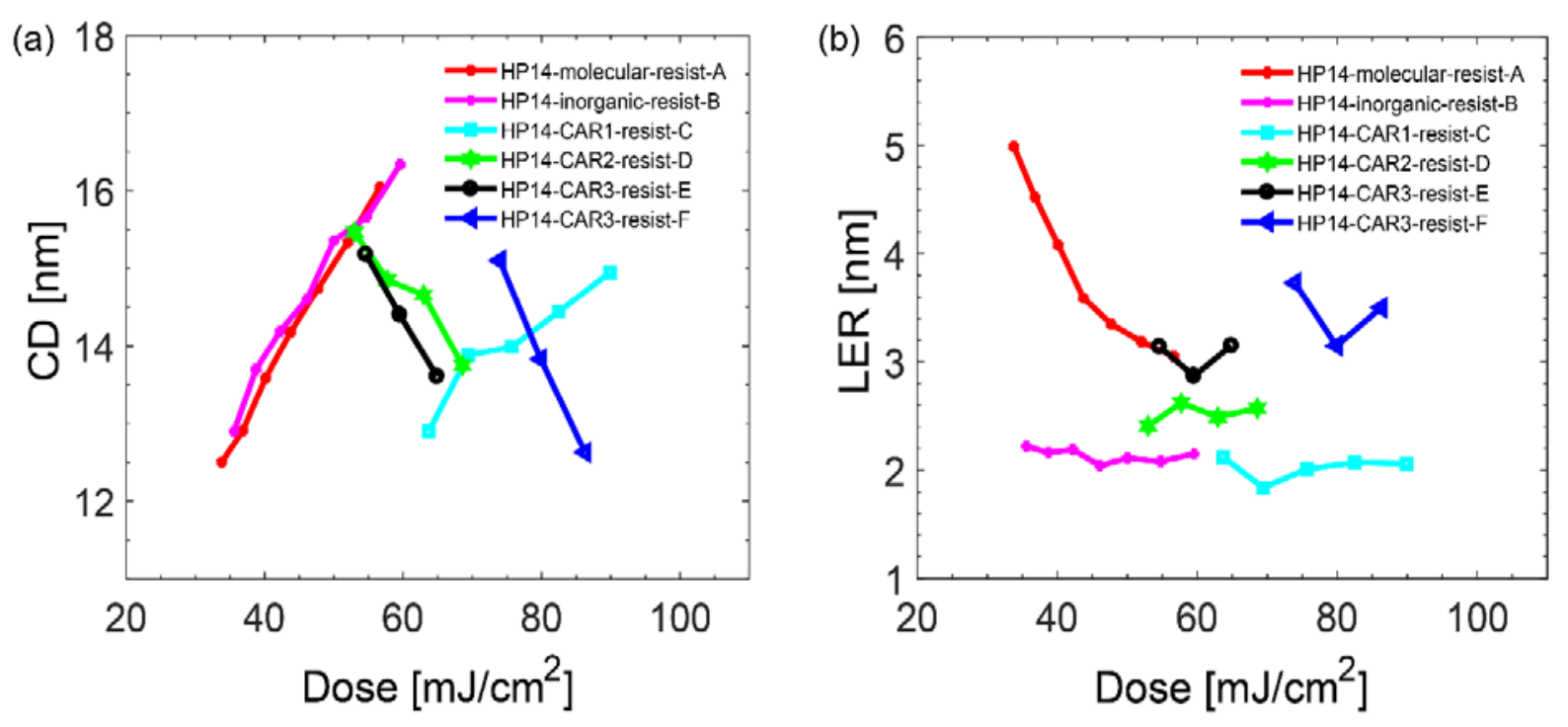

Figure 5. (a) CD to dose of the six best performance resists. (b) LER to dose of the six best performance resists.

Table 2. CD, Dose, EL and LER of the six best performance resists for HP $14 \mathrm{~nm}$.

\begin{tabular}{|c|c|c|c|c|c|}
\hline Vendor & Resist & Dose (mJ/cm $\left.{ }^{\mathbf{2}}\right)$ & EL (\%) & LER (nm) & $\begin{array}{c}\text { z-factor* } \mathbf{1 0}^{-\mathbf{8}} \text {, } \\
\mathbf{n m}^{\mathbf{3}} \mathbf{m J}\end{array}$ \\
\hline Vendor 1 & Molecular A & 41 & 13 & 3.5 & 1.4 \\
\hline Vendor 2 & Inorganic B & 42 & 20 & 2.1 & 0.5 \\
\hline Vendor 3 & CAR C & 69 & 27 & 1.8 & 0.6 \\
\hline Vendor 4 & CAR D & 60 & 23 & 2.4 & 0.9 \\
\hline Vendor 5 & CAR E & 64 & 4 & 3.1 & 1.7 \\
\hline Vendor 6 & CAR F & 79 & 39 & 3.1 & 2.1 \\
\hline
\end{tabular}

As the resolution goes higher to HP $14 \mathrm{~nm}$, we can see that the molecular resist A, inorganic resist B and CAR resist C are maintaining their performance. Although CAR D, E, and F resists also resolved HP $14 \mathrm{~nm}$, the blur appeared for both E and $\mathrm{F}$ resists, that means the increase of the LER. These resists demonstrated higher LER values (3.1 nm for both $\mathrm{E}$ and F), see Table 2. Similar to HP $16 \mathrm{~nm}$, molecular resist A resolved HP $14 \mathrm{~nm}$ at the lowest dose of $41 \mathrm{~mJ} / \mathrm{cm}^{2}$ with LER $3.5 \mathrm{~nm}$. The lowest LER is obtained for CAR resist C with higher dose $69 \mathrm{~mJ} / \mathrm{cm}^{2}$. The full comparison of different performance parameters including exposure latitude for the selected resists is shown in Table. 2.

From the comparison of the critical parameters (dose, EL, LER, z-factor), it can be concluded that the inorganic resist B could be a potential candidate for future technology nodes as it gives comprehensive good performance for both HP 16 $\mathrm{nm}$ and HP $14 \mathrm{~nm}$.

A good metric providing the overall performance of a resist is the Z-factor defined as [4]

$$
\text { Z-factor }=(\text { Sensitivity }) \times(\text { LER })^{2} \times(H P)^{3}
$$


This simple figure of merit of the resist performance is a simplistic model describing the interdependence of the acid blur, LER and sensitivity. The model was used here to identify the resists that might be interesting for HVM in semiconductor industry. We listed all the resists of the four resist platforms (molecular, inorganic, CAR and Metal-CAR) that have resolved HP $16 \mathrm{~nm}$ and HP $14 \mathrm{~nm}$, in Fig. 6(a) and (b), respectively. The solid curve is fitted with Eq. (3) (Fig. 6) and Z values are $6.9 \times 10^{-8}$ and $4.8 \times 10^{-8}$ respectively for HP $16 \mathrm{~nm}$ and HP $14 \mathrm{~nm}$, which were obtained in this study.

The rectangular green area is defined using the threshold values $\left(\mathrm{BE}<35 \mathrm{~mJ} / \mathrm{cm}^{2}\right.$, and LER $<4.6 \mathrm{~nm}$ for $\mathrm{HP} 16 \mathrm{~nm}$; BE $<$ $50 \mathrm{~mJ} / \mathrm{cm}^{2}$ and LER $<5.2 \mathrm{~nm}$ for HP $14 \mathrm{~nm}$ ) that we adopted to have a quantitative definition for selection of "resists with good performance" [10]. These values are not representing the industry targets but are the threshold values that we use for quantitative comparison. We see that there are only three resists (all molecular from one vendor) inside the 'window' for HP $16 \mathrm{~nm}$. Seven resists, including four molecular resists, one inorganic, one CAR and one metal-CAR, falling in the window for HP $14 \mathrm{~nm}$. We observed that the LER has been improved for CAR resists. The inorganic resist gives a low LER of $2.1 \mathrm{~nm}$ at a relatively low dose $\left(42 \mathrm{~mJ} / \mathrm{cm}^{2}\right)$ for $\mathrm{HP} 14 \mathrm{~nm}$, that again confirms that this resist will be a promising candidate for the future technology nodes.

To show the resolution limit of different resists, we listed the highest resolved HP versus the sensitivity (dose), in Fig. 7. The inorganic resist B reached HP $10 \mathrm{~nm}$ at dose $67 \mathrm{~mJ} / \mathrm{cm}^{2}$. The molecular resist reached $\mathrm{HP} 14 \mathrm{~nm}$ at the lowest dose $42 \mathrm{~mJ} / \mathrm{cm}^{2}$.
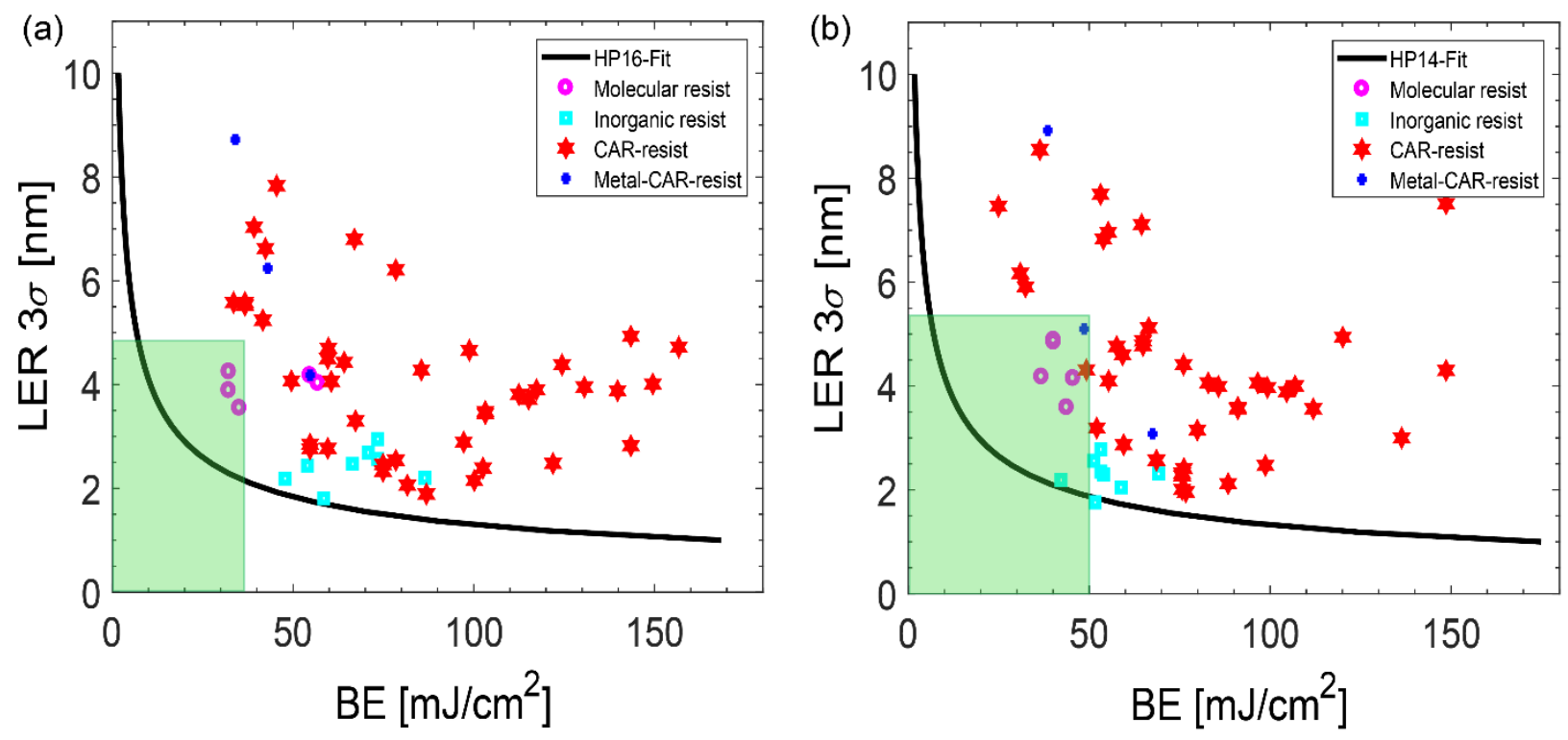

Figure 6. LER and BE values of the selected resists at HP $16 \mathrm{~nm}$ (a) and HP $14 \mathrm{~nm}$ (b) for different resists platforms. The solid curves represent the minimum Z-factor (Eq. (3)) obtained in this study. 


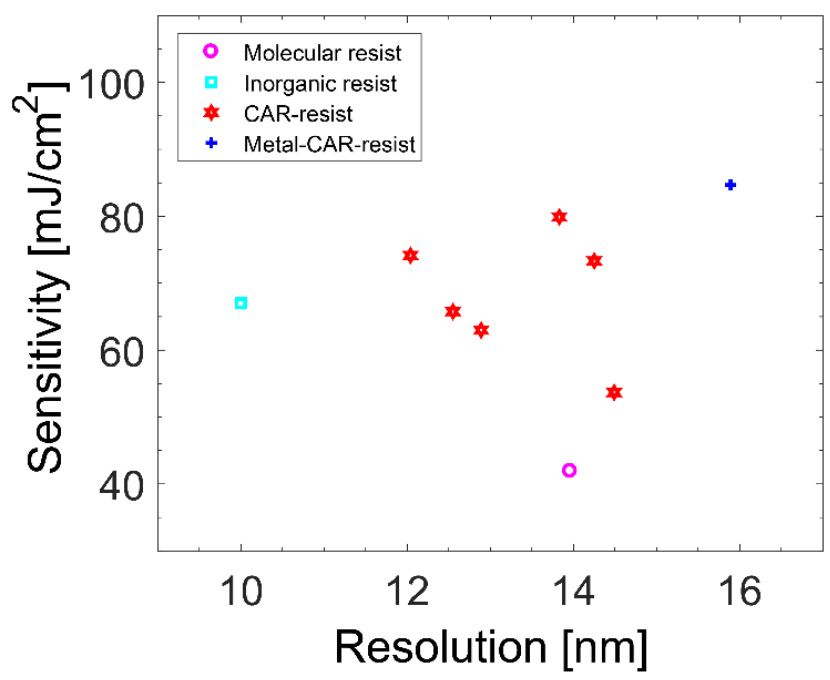

Figure 7. The sensitivity over the resolution of the best performance resists resolution down to HP $10 \mathrm{~nm}$.

\section{CONCLUSIONS}

We presented the results of EUV resists evaluated over the period of 2017-2018 with EUV-IL in the framework of our resist screening program. We have evaluated about 150 resists as well as their performance with different processing conditions, such as development, PAB, PEB, and resist film thickness. The resists were from 7 vendors and different resist platforms, such as CAR, metal-CAR, molecular, and inorganic resist, representing an almost complete spectrum of available resists.

We showed the results for the six selected resists at HP $16 \mathrm{~nm}$ and HP $14 \mathrm{~nm}$, which showed good performance and achieving resolution down to HP $14 \mathrm{~nm}$. We showed the several promising candidates - inorganic resist gives the lowest LER at a relatively low dose and high resolution down to HP $11 \mathrm{~nm}$, molecular resist lowest dose performance, CAR lowest LER. The molecular resist A had the best sensitivity to resolve both HP $16 \mathrm{~nm}$ and HP $14 \mathrm{~nm}$ but with high LER. The CAR resist $C$ provided the lowest LER but needed the highest dose. The inorganic resist $B$ shows comprehensive advantages by offering a very low LER and a quite broad EL. The inorganic resist B demonstrated a very high resolution capability with HP down to $10 \mathrm{~nm}$. From the evaluation results, it can be concluded that the inorganic resist B can be considered as a potential candidate for the HVM high-NA EUVL.

We would like to point out that although EUV-IL is an effective tool for resist evaluation, the values of dose, LER, and $\mathrm{CD}$ are specific to our tool and are not cross-calibrated with other resist testing platforms. EUV-IL provides a low-cost and flexible resist testing platform. It has high resolution and a well-defined aerial image and thereby enables development of EUV resists before high-NA EUVL tools become available. The LER and CD values are obtained with our in-house SEM which is a multi-purpose tool. We are aware that particularly LER is very sensitive to SEM settings and data analysis parameters. Although we try to keep these values constant and the quantitative comparison of different resists is sound, these values should be regarded as in-house values. The dose values of different resists reported here allow the comparison of the performance of different resists. However, the dose value obtained with another tool will depend on the profile and the contrast of the aerial image specific to the tool, illumination conditions and the exact targeted pattern. Our general experience is that our reported LER values are slightly higher than the values reported elsewhere and a resist with a good performance with EUV-IL will also perform well with another tool, although exact dose values will be different. 
In the future, to support the global efforts of EUV resist development, we will continue to monitor EUV resists for current and future technology nodes. We hope to see more resist progress and we are looking forward to working with more resist vendors.

\section{ACKNOWLEDGEMENTS}

We are grateful to Markus Kropf for his technical assistance. Part of this work was performed at Swiss Light Source (SLS), Paul Scherrer Institute.

\section{REFERENCES}

[1] M. v. d. Brink, "Cost-effective shrink with holistic lithography, extended by EUV,” Proc. EUVL Symp., Maastricht, The Netherlands, (2015).

[2] E. Buitrago, M. Meeuwissen, O. Yildirim, R. Custers, R. Hoefnagels, G. Rispens, M. Vockenhuber, I. Mochi, R. Fallica, Z. Tasdemir, and Y. Ekinci, "State-of-the-art EUV materials and processes for the 7nm node and beyond," Proc. SPIE, 10143, 8 (2017).

[3] C. Fouquet, "EUV Products and Business Opportunity," ASML SMALL TALK 2018., VELDHOVEN, The Netherlands, (2018).

[4] T. Wallow, C. Higgins, R. Brainard, K. Petrillo, W. Montgomery, C.-S. Koay, G. Denbeaux, O. Wood, and Y. Wei, [Evaluation of EUV resist materials for use at the $32 \mathrm{~nm}$ half-pitch node] SPIE, AL (2008).

[5] E. Buitrago, R. Fallica, D. Fan, T. S. Kulmala, M. Vockenhuber, and Y. Ekinci, "SnOx high-efficiency EUV interference lithography gratings towards the ultimate resolution in photolithography," Microelectronic Engineering, 155, 44-49 (2016).

[6] Y. Ekinci, M. Vockenhuber, B. Terhalle, M. Hojeij, L. Wang, and T. R. Younkin, "Evaluation of resist performance with EUV interference lithography for sub-22-nm patterning,” Proc. SPIE, 8322, 11 (2012).

[7] N. Mojarad, D. Fan, J. Gobrecht, and Y. Ekinci, "Broadband interference lithography at extreme ultraviolet and soft X-ray wavelengths,” Optics Letters, 39(8), 2286-2289 (2014).

[8] N. Mojarad, J. Gobrecht, and Y. Ekinci, "Interference lithography at EUV and soft X-ray wavelengths: Principles, methods, and applications,” Microelectronic Engineering, 143, 55-63 (2015).

[9] A. M. Goethals, R. Gronheid, F. Van Roey, H. H. Solak, and Y. Ekinci, "Progress in EUV Resist Performance," Journal of Photopolymer Science and Technology, 19(4), 501-506 (2006).

[10] E. Buitrago, S. Nagahara, O. Yildirim, H. Nakagawa, S. Tagawa, M. Meeuwissen, T. Nagai, T. Naruoka, C. Verspaget, R. Hoefnagels, G. Rispens, G. Shiraishi, Y. Terashita, Y. Minekawa, K. Yoshihara, A. Oshima, M. Vockenhuber, and Y. Ekinci, "Sensitivity enhancement of chemically amplified resists and performance study using extreme ultraviolet interference lithography,” Proc. SPIE, 15, 9 (2016).

[11] Z. Tasdemir, X. Wang, I. Mochi, L. v. Lent-Protasova, M. Meeuwissen, R. Custers, G. Rispens, R. Hoefnagels, and Y. Ekinci, [Evaluation of EUV resists for 5nm technology node and beyond], Proc. SPIE, 108090L (2018).

[12] N. Mojarad, M. Hojeij, L. Wang, J. Gobrecht, and Y. Ekinci, "Single-digit-resolution nanopatterning with extreme ultraviolet light for the $2.5 \mathrm{~nm}$ technology node and beyond," Nanoscale, 7(9), 4031-4037 (2015).

[13] D. Fan, and Y. Ekinci, "Photolithography reaches 6 nm half-pitch using EUV light," Proc. SPIE, 9776, 11 (2016).

[14] X. Wang, L.-T. Tseng, D. Kazazis, Z. Tasdemir, M. Vockenhuber, I. Mochi, and Y. Ekinci, [Studying resist performance for contact holes \rinting using EUV interference lithography] Proc. SPIE, 18.1. 013501 (2019).

[15] G. F. Lorusso, T. Sutani, V. Rutigliani, F. v. Roey, A. Moussa, A.-L. Charley, C. Mack, P. Naulleau, V. Constantoudis, M. Ikota, T. Ishimoto, and S. Koshihara, [The need for LWR metrology standardization: the imec roughness protocol] Proc. SPIE, 105850D(2018). 